\title{
A prospective study of effect of amniotic fluid index less than 5 at term on perinatal outcome
}

\author{
Padmini C. P.*, Chaitra R, Indra N, Sriram Adithya M
}

Department of Obstetrics and Gynaecology, Sri Siddhartha Medical College, Agalkote, Tumkur, Karnatka, India

Received: 25 April 2016

Revised: 14 May 2016

Accepted: 17 May 2016

\section{*Correspondence:}

Dr.Padmini C. P.,

E-mail: padmiinicp@gmail.com

Copyright: ( $)$ the author(s), publisher and licensee Medip Academy. This is an open-access article distributed under the terms of the Creative Commons Attribution Non-Commercial License, which permits unrestricted non-commercial use, distribution, and reproduction in any medium, provided the original work is properly cited.

\section{ABSTRACT}

Background: To study the effect of oligohydramnios in pregnancy and its value in predicting adverse perinatal outcome.

Methods: A prospective case control study of pregnancy outcome in 100 cases with ultrasound diagnosis of oligohydramnios at term compared with 100 controls with no oligohydramnios. The study was done over a period of 3 years at SSMC Tumkur, India.

Results: Oligohydramnios at term is associated with poor perinatal outcome. Significant increase in abnormal foetal heart rate, meconium stained liquor, delivery by cesarean section, low Apgar intrauterine growth restriction (IUGR), increased admissions to neonatal intensive-care unit (NICU) were seen in study group, however perinatal mortality was more in study group but not statistically significant $(\mathrm{P}=0.31)$

Conclusions: AFI $<5$ at term is an important fetal surveillance methods to identify poor perinatal outcome and thereby makes possible intervention so as to reduce perinatal morbidity and mortality.

Keywords: Oligohydramnios, Amniotic fluid index, Meconium stained liquor, Perinatal outcome

\section{INTRODUCTION}

Amniotic fluid which surrounds the developing fetus in amniotic sac provides a supportive environment for fetal development and is an important indicator of fetal wellbeing. ${ }^{1}$ Abnormality of amniotic fluid volume (AFV) is associated with increased incidence of perinatal mortality and morbidity. ${ }^{2-4}$ The amniotic fluid index (AFI) measured by the 4 quadrant ultrasonic technique was added to identify fetuses at higher risk of poor perinatal outcome.

Oligohydramnios is defined as amniotic fluid volume $<5 \mathrm{~cm}$, originally described by Phelan et al. Oligohydramnios is due to uteroplacental insufficiency. It is associated with structural anomalies, intrauterine gowth restriction, abnormal fetal heart rate (FHR) pattern, low Apgar score, pulmonary hypoplasia, increased risk of cesarean delivery and neonatal death. 5,6

In high risk pregnancies, oligohydramnios is frequently used to identify fetuses at risk of an adverse outcome. The purpose of this study was to evaluate the effect of oligohydramnios at term on perinatal outcome.

\section{METHODS}

A prospective case control study for 3 years in department of OBG, SSMC, Tumkur, Karnataka, India between March 2013 to January 2016. The study consists of 100 cases diagnosed as oligohydramnios at term with AFI <5 by USG compared with 100 controls with no oligohydramnios. Clearance from ethical committee taken matched for variables such as age, parity and 
gestational age. Consent from the patient was taken and cases satisfying the inclusion and exclusion criteria were studied.

\section{Inclusion criteria}

- Patients with 37 completed weeks of gestation.

- Intact membranes.

- $\mathrm{AFI}<5 \mathrm{~cm}$.

- Singleton pregnancy with cephalic presentation.

\section{Exclusion criteria}

- Multiple pregnancies.

- Rupture of membranes.

- Congenital anomalies of the fetus.

- Intrauterine death of the fetus.

- Postterm pregnancy.

- High risk pregnancy.
i. Preeclampsia.
ii. Diabetes.
iii. Chronic renal disease.

For all the selected cases through history was taken complete examination was done (systemic, per abdomen and pelvic examination), clinical evidence for oligohydramnios was looked for. Routine investigations like hemoglobin, blood group and $\mathrm{Rh}$ typing, urine examination was done. Non stress test was done for all patients. For all the pregnant women, ultrasound examination was done, and AFI was calculated by 4 quadrant amniotic fluid volume measurement technique. Oligohydramnios defined as AFI $\leq 5 \mathrm{~cm}$. The amniotic fluid volume is considered normal if AFI is between 5.1 $\mathrm{cm}$ and $20 \mathrm{~cm}$. for each case a control was taken with similar gravidity, parity, gestational age but the AFI, of more than $8 \mathrm{~cm}$ and $<20 \mathrm{~cm}$. The mean AFI for the study group was $3.55 \mathrm{~cm}$ and for the control group was $9.25 \mathrm{~cm}$.

Various perinatal outcome parameters recorded were abnormal fetal heart (non-reactive non-stress test (NST), colour of amniotic fluid (meconium stained liquor), mode of delivery, Apgar score, birth weight and admission to neonatal intensive care unit and perinatal mortality) and the results were statistically analysed.

\section{RESULTS}

Table 1 shows age distribution. The age of the patients ranges from 18-30 years. Majority of them belong to 21-25 years. The mean age was $22.82 \pm 2.83$ years.

The mean gestational age was 39.4 weeks for the study group and 39.5 weeks for the control group which was similar (Table 2).
Table 1: Age distribution.

\begin{tabular}{|lll|}
\hline Age & Distribution & $\mathbf{n = 1 0 0}$ \\
\hline $18-20$ & 20 & $20 \%$ \\
\hline $21-25$ & 68 & 68 \\
\hline $26-30$ & 12 & 12 \\
\hline Total & 100 & $100 \%$ \\
\hline
\end{tabular}

Table 2: Gestational age relationship to amniotic fluid index.

\begin{tabular}{|lll|}
\hline Age in weeks & Study $($ AFI $<5)$ & Control (AFI>5-24) \\
\hline $37-40$ & 24 & 41 \\
\hline $40-42$ & 26 & 9 \\
\hline Total & 50 & 50 \\
\hline
\end{tabular}

Table 3: Comparison of perinatal outcome parameters in study and control group.

\begin{tabular}{|lccccc|}
\hline $\begin{array}{l}\text { Outcome } \\
\text { parameters }\end{array}$ & No & $\%$ & No & $\%$ & p-value \\
\hline $\begin{array}{l}\text { Non-reactive } \\
\text { NST }\end{array}$ & 40 & 40 & 20 & 20 & 0.04 \\
\hline $\begin{array}{l}\text { Thick } \\
\text { meconium } \\
\text { stained } \\
\text { liquor }\end{array}$ & 48 & 48 & 18 & 18 & 0.001 \\
\hline LSCS & 62 & 62 & 24 & 24 & 0.0001 \\
\hline Apgar score $<7$ & 38 & 38 & 20 & 20 & 0.04 \\
\hline $\begin{array}{l}1 \text { min } \\
5 \text { min }\end{array}$ & 8 & 8 & 4 & 4 & 0.04 \\
\hline $\begin{array}{l}\text { Birth weight } \\
\text { kg }\end{array}$ & 64 & 64 & 16 & 16 & 0.0095 \\
\hline $\begin{array}{l}\text { Admission to } \\
\text { NICU ward }\end{array}$ & 44 & 44 & 14 & $14 \%$ & 0.0007 \\
\hline $\begin{array}{l}\text { Perinatal } \\
\text { mortality }\end{array}$ & 2 & 2 & 0 & 0 & 0.31 \\
\hline
\end{tabular}

NST was not reactive in $40 \%$ in study group as compared to $20 \%$ in control group with a p-value of 0.04 . Variable deceleration was the most common fetal heart rate (FHR) abnormality in study group. Meconium stained liquor was seen in $48 \%$ in study group $18 \%$ in control group with a p-value of 0.01. Incidence of LSCS, low Apgar IUGR, admission to NICU and perinatal mortality was more in study group (Table 3).

\section{DISCUSSION}

Oligohydramnios defined as amniotic fluid index $\leq 5 \mathrm{~cm}$ or $<5^{\text {th }}$ percentile for gestational age. Antepartum oligohydramnios increases the risk of meconium staining, intrapartum cardiotocographic abnormalities and operative delivery for fetal distress. ${ }^{8}$

Because oligohydramnios has been circumstantially associated with a variety of ominous pregnancy outcome such as perinatal death, fetal distress in labor and poor 
infant condition at birth, obstetricians have increasingly resorted to induction of labor or antepartum testing of fetal health in pregnancies complicated by decreased amniotic fluid volume. ${ }^{9}$

Table 4: The results of outcomes of present study are comparable with results of similar studies.

\begin{tabular}{|llllll|}
\hline & Sriya R et al & Chandra P et al & Kumar P et al & Umber et al & Present study \\
\hline Non reactive NST & $41.55 \%$ & $69.23 \%$ & $40 \%$ & $52.7 \%$ & $40 \%$ \\
\hline Thick meconium stained liquor & $38.8 \%$ & $23.7 \%$ & - & $6 \%$ & $48 \%$ \\
\hline LSCS & $43.05 \%$ & $76.92 \%$ & $63.1 \%$ & $32 \%$ & $62 \%$ \\
\hline Apgar & & & & & \\
\hline 1 minute & $38.8 \%$ & - & - & $8 \%$ & $38 \%$ \\
\hline 5 minute & $9.72 \%$ & $23.07 \%$ & - & $6 \%$ & $8 \%$ \\
\hline Birth weight $<2.5 \mathrm{~kg}$ & $58.38 \%$ & $61.53 \%$ & - & $36.3 \%$ & $64 \%$ \\
\hline Admission to NICU & $88.88 \%$ & $46.15 \%$ & - & $7 \%$ & $44 \%$ \\
\hline
\end{tabular}

Non-reactive NST was seen in $40 \%$ of patients in present study which is similar to studies done by Sriya et al and Kumar et al. ${ }^{10,9}$ In study done by Chandra et al incidence of LSCS was $62 \%$ in present study as compared to 63.1 and 76.92 in Kumar $\mathrm{P}$ et al and Chandra et al study (Table 4). ${ }^{10,13}$

The occurrence of meconium stained liquor was more in women with oligohydramnios i.e., $48 \%$ which is comparable to study by Rutherford, which is $54 \%$. Various studies show different rates of LSCS for fetal distress in pregnant women with oligohydramnios. $66.7 \%, 76.92 \%$ and $43.05 \%$ in studies done by Kumar P et al Chandra et al and Sriya $\mathrm{R}$ et al. ${ }^{10,11,13}$ The 5 minute Apgar of less than 7 in study group was $8 \%$ in present study and $7 \%$ new borns were admitted to NICU with morbidities like birth asphyxia and meconium aspiration. This is comparable to studies by Chandra et al. ${ }^{13}$ The study by Sriya et al showed higher incidence of admissions to NICU i.e $88.8 \% .^{11}$

There were 2 perinatal deaths in study group and no death in control group as compared with 1 death in Chandra $\mathrm{P}$ et al study. There were no neonatal death in Baron and Casey et al study. ${ }^{9,12}$ The 2 neontal death in present study were due to meconium aspiration syndrome.

\section{Funding: No funding sources}

Conflict of interest: None declared

Ethical approval: The study was approved by the Institutional Ethics Committee

\section{REFERENCES}

1. Brace RA. Physiology of amniotic fluid volume regulation. Clin obstet Gynecol. 1997;40:250-89.

2. Manning FA, Hill LM, Platt LD. Quantitative amniotic fluid volume determination by ultrasound, antepartum detection of intrauterine growth retardation. Am J Obstet Gynecol. 1981;139:254.
3. Mercer LJ, Brown LG, Petres RE, Messer RH. A survey of pregnancies complicated by decreased amniotic fluid. Am J Obstet Gynecol. 1984;149:355.

4. Philipson EH, Sokol RJ and Williams T. Oligohydromnios; clinical associations and predictive value for intrauterine growth restriction. Am J Obstet Gynecol. 1983;146:271.

5. Brendan CC, Brunner JP. Umblical artery doppler velocimetry in pregnancies complicated by oligohydromnios. J Rep Med. 2000;45:563-66.

6. Chauhan SP, Sanderson M, Hendrix NW, Magan EF, Devoe LD. Perinatal outcome and amniotic fluid index in antepartum and intrapartum periods; a meta-analysis. Am J Obstete Gynecol. 1999;161:1473-8.

7. Phelan JP, Smith CV, Broussard P, Small M. Amniotic fluid index assessment using the four quadrant technique in the pregnancy between 36 and 42 weeks gestation. J Reprod Med. 1987;32(7);5402.

8. Robson SC, Crawford RA, Spencer AD, Lee A. Intrapartum amniotic fluid index and its relationship to fetal distress. Am J Obstet Gynecol. 1992;166:7882.

9. Casey BM, Mclntire DD, Bloom SL, Lucas MJ, Santos R, Twickler DM, et al. Pregnancy outcomes after antepartum diagnosis of oligohydramnios at or beyond 34 weeks gestation. Am J Obstet Gynecol. 2000;189:909-12.

10. Kumar P, Iyer S, Ravikumar V. Amniotic fluid index-A new ultrasound assessment of amniotic fluid. Obstet Gynecol India.1991;10-12.

11. Sriya R, Singhai S. Perinatal outcome in patients with amniotic fluid index $<5 \mathrm{~cm}$. J Obstet Gynaecol India 2001;51:98-100.

12. Baron C, Morgan MA, Garite TJ. The impact of amniotic fluid volume assessed intrapartum on perinatal outcome. Am J Obstet Gynecol. 1995; 173:167-74.

13. Chandra P, Kaur SP, Hans DK. The impact of amniotic fluid volume assessed intrapartum on 
perinatal outcome. Obstet Gynaecol. 2000;5(8):17881.

14. Umber A. Perinatal outcome in pregnancies complicated by isolated oligohydramnios at term. Annals. 2009;15;35-7.
Cite this article as: Padmini $\mathrm{CP}$, Chaitra R, Indra N, Sriram AM. A prospective study of effect of amniotic fluid index less than 5 at term on perinatal outcome. Int J Reprod Contracept Obstet Gynecol 2016;5:1732-5. 